Article

\title{
An Augmented Reality Children's Book Edutainment through Participatory Content Creation and Promotion Based on the Pastoral Life of Psiloritis ${ }^{\dagger}$
}

\author{
Antonis Ntagiantas ${ }^{1}$, Markos Konstantakis ${ }^{1, *(\mathbb{D}}$, John Aliprantis ${ }^{1}$, Dimitris Manousos ${ }^{2}$, Lefteris Koumakis ${ }^{2} \mathbb{D}$ \\ and George Caridakis ${ }^{1}$ \\ 1 Department of Cultural Technology and Communication, 81100 Mytilene, Greece; \\ antagiantas@gmail.com (A.N.); jalip@aegean.gr (J.A.); gcari@aegean.gr (G.C.) \\ 2 Institute of Computer Science, Foundation for Research and Technology Hellas, 70013 Heraklion, Greece; \\ mandim@ics.forth.gr (D.M.); koumakis@ics.forth.gr (L.K.) \\ * Correspondence: mkonstadakis@aegean.gr \\ $+\quad$ This paper is an extended version of our paper published in 2021 16th International Workshop on Semantic \\ and Social Media Adaptation \& Personalization (SMAP), Online, 4-5 November 2021.
}

Citation: Ntagiantas, A.;

Konstantakis, M.; Aliprantis, J.;

Manousos, D.; Koumakis, L.;

Caridakis, G. An Augmented Reality Children's Book Edutainment through Participatory Content Creation and Promotion Based on the Pastoral Life of Psiloritis. Appl. Sci. 2022, 12, 1339. https://doi.org/ 10.3390/app12031339

Academic Editor: João M. F. Rodrigues

Received: 30 December 2021

Accepted: 26 January 2022

Published: 27 January 2022

Publisher's Note: MDPI stays neutral with regard to jurisdictional claims in published maps and institutional affiliations.

Copyright: (C) 2022 by the authors. Licensee MDPI, Basel, Switzerland. This article is an open access article distributed under the terms and conditions of the Creative Commons Attribution (CC BY) license (https:// creativecommons.org/licenses/by/ $4.0 /)$.

\begin{abstract}
Augmented reality (AR) provides excellent learning potential, especially in a school environment. Multiple students can share the virtual scene and interact with it using the mobile interface as a hand-held display in AR children's books. Students' participation is an essential element of learning, and one of AR's greatest strengths is its ability to promote collaborative experiences. An augmented reality children's book edutainment through participatory content creation and promotion based on the pastoral life of Psiloritis has been recommended through this study, highlighting the features of AR to reveal educational values unique to AR and studying approaches for incorporating these characteristics into the typical education curriculum.
\end{abstract}

Keywords: augmented reality; digital book; digital storytelling; serious games; edutainment; content creation; participatory design; intangible cultural heritage; collaboration

\section{Introduction}

Augmented reality (AR) is a technology with great potential in teaching and learning, while it offers innovative ways to educate [1]. Many studies have already investigated new methods that integrate AR techniques in education, enhancing the learning experience and introducing new ways to help students improve their academic performances [2,3]. Traditional methods such as simple lectures with educators soliloquising their knowledge are considered ineffective and non-interactive and, thus, incapable of stimulating students' interest [1]. As a result, educators seek better methods to enhance their students' learning experience.

One of the critical aspects in AR implementation with learning procedures is student's collaboration. Users can share the same visual scene, interact simultaneously with the digital information, and improve their learning procedures. Meanwhile, textbook-based AR involves primary school children and their teachers in a collaborative learning experience that increases their motivation through interactive approaches.

This project aims to create an augmented reality application of children's books to promote intangible cultural heritage through participatory content creation by users. With essential tools in interaction and cooperation with the people who live and work in the mountainous environment of Psiloritis, a technological solution will emerge to promote and protect the intangible cultural heritage of the mountain. Essentially, an augmented reality application for children and students will be created so that with the use of new AR technologies, scenes, and heroic traditions from a mountain with its shepherd as the 
timeless protagonist will be able to come to life and contribute to the exchange of knowledge and know-how in areas with corresponding elements of intangible cultural heritage.

The case study of our research is the pastoral life of Psiloritis as a UNESCO World Geopark [4]. The book will describe the pastoral life in Psiloritis combined with mythology, archaeological data, and the region's history through a children's story. At the same time, through the life of man in nature, the importance of protecting the environment will be presented, transmitting it to the next generation in the most modern way. Our focus is to explore how AR technology promotes and preserves intangible cultural heritage through participatory content creation. The book and the application will be available in two languages. People outside Greece can contribute cultural elements, and know-how can be exchanged with other regions with different cultures and traditions.

The contribution per section and the structure of this paper is as follows: Section 2 provides a brief overview of the paper's background knowledge and main principles. Section 3 presents the state of the art in augmented reality children's books. Section 4 presents the methodological approach, providing a concise and precise description of the AR book architecture, the AR book prototype, and the AR book user personas and use case scenarios. Section 5 presents an evaluation procedure of the proposed AR book. Finally, Section 6 concludes the paper.

\section{Background Knowledge}

This section presents background knowledge necessary for understanding the concept of an augmented reality edutainment children's book system.

\subsection{Augmented Reality}

Particularly in the $\mathrm{CH}$ (Cultural Heritage) domain, AR has proved to be rather effective in presenting cultural heritage information, enhancing visitors' experience with various types of multimedia, combining entertainment and education [5-9]. Many recent studies have shown that $A R$ is recognised as a technology with increasing value for innovation and enhancing the visitor experience [8-10]. AR enhances location-based learning because it helps learners connect historical sites with their prior knowledge and provides additional new knowledge relevant to them [11]. It is a technology that can "animate" archaeological sites, "repair" damaged statues and objects, "reconstruct" monuments that have been lost over the years and provide the exhibits of the museums with the ability to "talk" to the visitor and give more information about their story (digital storytelling).

Integrating AR techniques with cultural heritage applications results in significant improvements for the cultural user's experience [12]. First, AR applications provide information no longer printed on information boards. Therefore, there is no need to alter the cultural site while AR software can easily modify or update digital data. In the same way, AR applications can provide "unlimited" and dynamic information to users. Furthermore, as a state-of-the-art technology that can display customised digital information in users' own devices, AR can improve customer satisfaction, generate positive word of mouth and increase attendance for the cultural institutions. Since AR applications usually allow real-time visitor experience sharing through online community applications, integrating AR techniques in cultural applications can also generate higher attendance and awareness [13].

Nowadays, various cutting-edge techniques are used in culture heritage AR apps to improve user experience, such as context awareness to deliver information relevant to the user's work or digital storytelling that allows users to listen to their object of interest's story. The usefulness of digital storytelling in the context of AR experiences has been underlined by several studies $[14,15]$. This project examines the benefits of integrating AR techniques in a painting that "interacts" with visitors through digital storytelling, enhancing the relations between the user, narration, and context. 


\subsection{Digital Storytelling}

Storytelling is a popular way to elicit emotional responses, communicate, and express cultural and personality traits. People may gain psychologically and emotionally from their own stories, and researchers continue to grow and improve as storytellers after all these years. Narratologists believe that a text must tell a story, exist in a world, be placed in time, contain intelligent agents, and have some causal sequence of events to be considered a narrative. Simultaneously, it generally aims to communicate something significant to an audience [16].

Digital storytelling (DS) obtains its compelling power from the integration of visuals, music, story, and voice. As a result, technologies such as AR may impact how museums deliver their narratives and show cultural heritage information to visitors. AR may be thought of as a mediation that uses interactivity and customisation to support narratives. Visitors can participate in or construct their own narrative situations throughout their cultural tour.

Digital storytelling is widely recognised as a powerful means for augmenting people's engagement and achieving the goal of communicating knowledge. Digital storytelling is characterised by giving the content a paced and exciting narrative structure. The term "digital storytelling" evokes "a story that integrates digital images, music and the author's voice in a short video or a multimedia presentation". Over the years, digital storytelling has primarily been used in two ways: the first is based on a traditional model, which provides an autobiographical narrative in digital format via first-person audio narration and is characterised by a linear and closed structure, similar to traditional narrative. The alternate way is marked by much more interaction, which immerses the audience in history, allowing it to participate fully and influence trends, all while utilising more media components (pictures, texts, audio, video, and music) and avoiding the use of audio narration [17].

Several studies [18-21] have emphasised the value of digital storytelling in the context of CUX (Cultural User eXperience). Nowadays, cultural areas must compete with the vast entertainment industry's offering. As a result, they should make their "product" more desirable and appealing to a wide range of consumers while adding extra features that blend instructional and entertaining elements. One of the "vehicles" they have for enhancing their offering is digital storytelling.

\subsection{User Personalisation}

Personalisation has become more critical in computer science, particularly in recommendation systems. A recommender system may interact with many users, each of whom has their unique set of preferences. The recommender system is responsible for addressing the needs of each user by recommending user-specific content or adjusting itself to meet those needs. As a result, the user profile improves the recommender system in understanding user requirements and acting accordingly.

The technique of identifying data about a user's activity is known as user profiling. The system may utilise this information to learn more about the user, and this knowledge can then be applied to improving retrieval and ensuring the user's satisfaction. User profiling involves two crucial aspects: effectively understanding the user and proposing content of his interest based on that knowledge [22].

When a visitor uses a system for the first time, the system will most likely fail to recommend content to the user effectively. This problem is commonly known as cold start and is common in recommendation systems. Many solutions and methods have been proposed to address the cold start issue.

Standard recommendation strategies are based on association rules and clustering techniques [23], social information [24], ontological classification of knowledge [25] and hybrid user modelling [26]. Multiple methods have been proposed to address the user profiling and classification task, particularly in the $\mathrm{CH}$ domain, improving the overall $\mathrm{UX}$. A relatively common technique is classifying users under persona profiles based on replies to multiple-choice queries. 
Hameed et al. [27] employed heuristic techniques to represent the requirements of distinct groups of visitors, whereas [18] used personas to convey the needs of different groups of visitors. Others asked users direct questions to establish their profiles, although research has shown that visitors dislike direct questioning [28]. Because direct asking was viewed as invasive, [29] took a detour and invited visitors to create avatars mirroring their personality attributes. Because visitors' time is limited and important, some tactics were more subtle and did not necessitate any visitor behaviours. One research, for example, simply monitored how visitors walked throughout museums and matched their movement patterns to personality traits [30]. As a result, it appears that such feedback acquisition methodologies used to deal with the cold start problem differ and may be classified as explicit (needing visitor activities) or implicit (not requiring visitor actions). Moreover, explicit ways might be direct (asking the visitor questions) or indirect (using the visitor in an activity that does not appear to be directly connected to profiling, such as games) [31].

While user profiling is beneficial in cultural heritage, establishing accurate visitor profiles is difficult due to the short time of most trips and the fact that most people would only visit a particular place once. Within these time constraints, visitor profiles must be developed fast and efficiently in terms of their suitability for various visitors. The difficulty is that, while visitors appreciate the benefits of customisation in cultural heritage, they are averse to form-filling activities. Researchers must become more innovative in collecting the necessary data to build user profiles.

Indeed, creating user profiles as "fictional" characters based on real data and research and tailored to a specific audience is regarded as a very consistent and representative method of defining genuine users and their objectives. However, it is critical to determine the precise (minimum) number of personas for each occasion to concentrate on the visitor characteristics to be investigated.

As a design tool, personas effectively communicate behaviours, objectives, desires, requirements, and frustrations. The purpose of developing a collection of personas is to depict the variety of observable motives, behaviours, attitudes, aptitudes, mental models, work or activity flows, settings, and problems with existing comparable systems if any.

Additionally, the identification process must use ubiquitous properties to overcome the cold start issue. Given that a user's visit to a cultural place may be used to infer features about his persona through an analysis of his visit's spatial and temporal course, it may be beneficial to construct sufficient physical infrastructure that enables this capability. The ideal technique would incorporate such possible input sources, allowing for a more rapid identification procedure without any prior data on the user, partially resolving the cold start problem [22].

\subsection{Serious Games}

Serious games (SGs) are commonly used in the field of cultural heritage [32-35]. The fact that SGs integrate learning components with the fun of video games creates a compelling game experience (GX) [36] and maximises user motivation. An SG's primary characteristic is its goal of assisting the player in achieving learning objectives through an enjoyable experience. The enjoyable element of an SG contributes to its engagement and is governed by a variety of aspects, including the storyline, visuals, usability, collaboration/competition systems and interaction devices.

One of the primary benefits of SGs is that they stimulate users to activate and expand their knowledge by converting them from passive data receivers to actors [37] who play, explore, make errors, and make their own decisions. Adaptive SGs have been shown to boost user motivation, acceptability, and identification [38]. Personalised and adaptable learning games may enable all participants to learn in a motivating manner since they consider that each individual has a unique learning style.

Serious games (SGs) are considered as applications that combine aspects of learning with the playfulness of video games. At the same time, they can also create an engaging game experience that maximises users' interest and motivation. Meanwhile, state of the art 
technologies such as augmented reality (AR) have been integrated into gaming applications, increasing users' motivating potential in learning contexts. Combining AR techniques in games makes it possible to merge working, learning and entertainment, shaping the traditional concept of education and fun in an entirely new perspective, simultaneously experiencing both the physical and the virtual world. In particular, SGs can exploit AR techniques for their development, with the prospect of new possibilities such as generating a deeper level of engagement during a game experience that educates through fun. Furthermore, the SGs-AR integration can provide a smooth transition between reality and virtuality, combine interaction between real and virtual environments, improve usability and provide a more natural and intuitive interaction [34].

Serious games have been increasingly used to teach History and Culture in recent years. SGs are a collection of digital games that promote learning via entertainment and are commonly utilised in cultural education. The graphical user interface (GUI) and user experience (UX) of serious games are critical characteristics, even more so when the target learners are children and teens. An instructional game must be visually appealing and provide an experience comparable to the digital entertainment games youngsters are most accustomed to today [39].

\subsection{D Model Representation}

Modern techniques have been utilised to record, preserve and recreate cultural heritage objects and sites in recent years. Three-dimensional modelling allows researchers to accurately represent cultural artefacts, objects, surfaces or structures, replicating their morphology, texture and colour. As a result, these representations can become valuable assets for preserving cultural heritage [40].

Three-dimensional modelling can be a helpful, non-invasive procedure for researchers to analyse morphology, architecture, textures, etc., comprehensively. Furthermore, it offers the ability to share information by digitally recreating the original cultural artefact. Since the physical access to many of these cultural objects and places is restricted or hard to reach, 3D modelling brings these cultural data to a much wider audience. Digitising cultural objects and heritage sites is a reliable and accurate way to preserve cultural information for the future [41].

Finally, 3D modelling provides a state-of-the-art interaction technique between users or scholars and cultural objects or cultural heritage sites. This technology enhances conserving and preserving cultural heritage by creating digital resources with accurate data that can be easily analysed, archived, and presented.

\subsection{Content Creation and Promotion-Crowdsourcing}

Through an open invitation, crowdsourcing is the act of outsourcing duties usually handled by an employee or contractor to a large number of volunteers or a community.

Jeff Howe and Mark Robinson [42], editors at Wired, created the phrase "crowdsourcing" to describe how corporations were utilising the Internet to "outsource labour to the crowd", which swiftly evolved into the portmanteau "crowdsourcing". Howe [43] coined the phrase crowdsourcing in a blog post accompanying his June 2006 Wired article, "The Rise of Crowdsourcing", published in print two days later.

According to the widely accepted definition on Wikipedia, "Crowdsourcing is a type of collective activity conducted over the internet in which an individual, an institution, a non-profit organisation, or a business invites a group of people with a wealth of knowledge, diversity, and size to volunteer for a job. Undertaking the task, which varies in complexity and degree of division and the crowd is required to engage through personal labour, money, expertise, and experience always results in a mutual gain for both parties. The participating users receive the satisfaction of a need, whether economic or social recognition, personal fulfilment, or the development of specific skills in a field, while the agile of the initiative (crowd sourcer) acquires and uses what the user contributes to the project, which varies according to the activity undertaken by the user". 
By comparing the preceding definition, we can identify some key characteristics of this concept: To begin, we can observe that crowdsourcing is open to any natural or legal person. To obtain the best potential findings, the objective is to assemble as many and as diverse individuals as possible in terms of age, education and so on.

The most frequently cited motives for these individuals to join the crowd are financial, personal or experience. In most circumstances, we are discussing a fundamentally voluntary idea, which is why the concept of volunteering frequently incorporates the idea of crowdsourcing.

The organisation that is presently organising this activity gathers and analyses all of the generated data in accordance with the duty assigned to them.

Jeff Howe [43], the pioneer of this notion, classified it into four broad categories: crowdfunding (collectively raising finance), crowd creation (forming collectives), crowd voting (collective voting) and crowd wisdom. To help you better comprehend the phrase, we have listed its six major stages below. The steps (crowdsourcing) are as follows:

- The company faces a problem.

- The company transmits the issue online.

- The online public submits solutions.

- The public and the company make solutions together.

- The company rewards the people who gave the "winning" solution.

- $\quad$ The company and society receive the benefits.

Lately, more and more organisations have been using crowdsourcing as a new model for content creation. New online technologies are used to assign tasks traditionally performed by an expert or a small team of specialists to a sizeable indeterminate group of people. Crowdsourcing is a new example of using the power of "crowd" people to facilitate large-scale tasks that are costly or time-consuming with traditional methods.

Meanwhile, the rapid increase in mobile devices (smartphones, tablets, watches, etc.) and social media have provided a connection platform that unlocked the vast potential of crowdsourcing and have become a valuable tool for increasing participation. In mobile crowdsourcing, devices are used for data collection tasks assigned to more people and for coordination between the individuals involved (Figure 1).

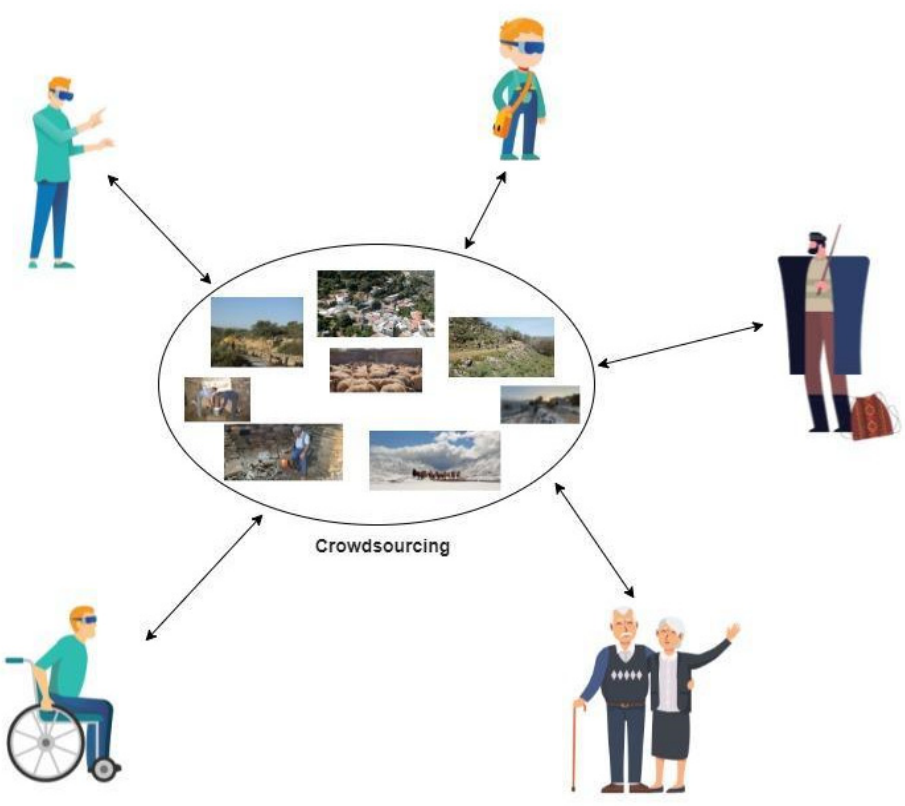

Figure 1. Crowdsourcing in AR book. 


\subsection{Recommendation Systems}

User-adaptive systems have gained popularity in a variety of application areas in recent years, including cultural tourism, which is currently acknowledged as one of the most significant kinds of tourist traffic. The spread of user-adaptive recommender systems (RS) in this field is accelerating, as cultural tourism is intrinsically linked to the tourists' own desires and interests [44]. While the abundance of resources and data accessible online have facilitated the rapid spread of cultural knowledge, they have also contributed to the problem of information overload; that is, the difficulty of finding the most appropriate resources for each individual's requirements.

Thus, managing these massive resources using important data analytics' principles and methodologies to provide visitors with appropriate and personalised assistance is one of the most intriguing issues in this study field. In this regard, it is critical to divide cultural tourists based on their overall cultural experiences. While cultural tourism has grown in popularity and growth, little study has been conducted to categorise cultural tourists based on their cultural centrality (e.g., cultural motive, the relevance of culture in the choice to travel) and depth/levels of cultural experience [45-47].

It is obvious that encountering cultural assets influences a person's travel decisions. On the other hand, cultural tourism destinations require a more accurate classification of their visitors and their underlying motives. Not everyone is driven to learn, experiment, or self-explore for the same reasons. Due to this premise that cultural tourists are not all the same, most of the literature on cultural tourism takes a segmentation approach, focusing on defining the cultural tourist typology [48]. McKercher [49] responded by developing a relevant typology based on two essential dimensions: cultural centrality and user experience depth. The typology above provides a valuable and practical framework for segmenting cultural tourists, validated, and used in the following empirical investigations [50,51].

In this aspect, RS are a critical component in delivering personalised content to a destination's visitors. RS are computer programmes that attempt to mimic users' tastes based on their encounters with the places they frequent. This interaction is often multimodal; it can be explicit when users actively review a location they visit or implicit when the system deduces the interaction between a visitor and a place. In the first scenario, opinion can be communicated in various ways, including through ratings on a specified scale (like/dislike, 5 -star system, etc.), questionnaire responses or even free-form writing (comments, etc.). In the latter situation, the user's preferences are determined by their activities, such as visiting to a location or snapping photographs. Naturally, the former contact style is preferred since it is more directly tied to the visitor's genuine preferences. However, for this to be effective, it requires a high degree of user involvement, which cannot be guaranteed for every potential user.

RS are a critical tool for resolving the aforementioned challenges and enabling travellers to make the best choices. In theory, a well-designed and successful RS may assist a cultural tourist in researching, comparing and selecting the most appropriate places that match their interests and specific needs. The majority of current RS functions by modelling both possible visitors and destinations; that is, by analysing their users' previous encounters with the places they've visited and their stated preferences, which are often expressed on a rating system. To give users personalised suggestions, RS ultimately choose the most relevant places that match the profile of the modelled user. As a result, user profiles are a fundamental component of RS, contributing significantly to their efficacy [52]. In this regard, every new piece of information about a user's preferences is likely to increase the quality of the suggestions even further.

Recent developments in digital technologies within the $\mathrm{CH}$ domain have driven technological trends in comfortable and convenient travelling by offering interactive and personalised user experiences. The emergence of recommendation systems in personalisation services has created an intelligent research field, augmenting cultural visitors' experiences. 


\subsection{Evaluation}

Much research has examined how to enhance the visitor experience in cultural places in various ways $[20,37]$. For instance, some scholars examined the tourist experience philosophically, while others examined many components of the visitor experience experimentally, including cognitive, intellectual, and emotional dimensions. Finally, others have examined the connection between individuals and exhibitions and between groups of visitors and exhibits. Additionally, each study's technology was customised to the requirements of the local cultural environment.

Additionally, cultural venues have incorporated quickly evolving technology over the last decade, and some of the technologies employed now may become obsolete shortly. With continual changes in the way cultural institutions build exhibitions to include new technologies, it is vital to investigate the effects of these technologies and the assessment approaches that address them on visitor experiences.

Thus, incorporating UX into $\mathrm{CH}$ (cultural heritage) is critical since it deals with "users' judgments of product quality based on their interaction experience, as well as the product characteristics that promote successful usage and enjoyment." This might be seen as incorporating $\mathrm{UX}$ into the digitisation and preservation of cultural heritage to guarantee that end-users have a favourable experience while engaging with digital collections.

While user-experience research techniques are excellent for generating data and insights, continuous actions assist in obtaining the correct things completed. Ongoing UX initiatives can help to maximise the effectiveness and value of everyone's work. At each level of the design process, several UX techniques may help keep product development efforts on track and in line with real user demands, not fictitious ones. At any stage during the design cycle, user research may be conducted. Evaluating cultural tourists' experiences is critical to this study's outcome and validation of the research aims. Recent decades have seen a revolution in studies of cultural spaces due to a shift in direction and the methodologies utilised to research the cultural areas themselves. Several approaches assist this type of study, including qualitative, quantitative, experimental and grounded theory [53].

The technique utilised in each research endeavour is determined by the scope and objectives of the investigation. Additionally, the approach chosen must be compatible with the components being analysed. Currently, museum educators, researchers and curators can choose from various assessment methodologies, including formative evaluation, summative evaluation and front-end evaluation.

\section{State of the Art in Augmented Reality Children's Books}

Numerous apps have been developed that utilise augmented reality techniques in conjunction with a book, mainly presenting relevant instructional information to the visitor. The motivation for using such strategies is that cultural heritage apps must offer a large quantity of data, which must be filtered to make it easily accessible to the particular user.

More precisely, the Live Solar System (LSS) is an augmented reality (AR) instructional application designed to assist students in learning about astronomy. As a result, LSS incorporates a variety of multimedia components such as video, images, text, and 3D objects to accomplish its objective. It is implemented by capturing the actual world image using a webcam and then sending it to the marker detection procedure. After the marker's ID is identified, associated digital items such as 3D objects will be loaded. The collected real-world vision will then be mixed with digital material and sent to users via HMD or display. The cube was utilised as the input device in LSS. LSS enables students to freely explore the AR solar system to understand the solar system's eight planets better. Additionally, kids may learn about the planets' properties, such as their suns, and their phenomena, by combining physical and digital learning resources [54].

Additionally, the augmented reality mobile technology [11] can guide student visits through interactive texts, photos, and audio information to learn about cultural heritage. The virtual multimedia information enables users to explore and obtain route/landmark/ survey knowledge for the adjacent heritage sites' geographic space. Chang et al. revealed 
that as compared to voice instruction, augmented reality guidance enhanced visitors' feeling of the location more effectively.

Hta [55] conceptualised and created an interactive spatial augmented reality (iSAR) book on Myanmar's cultural heritage. This iSAR book contains 18 pages of rich media material, including films, animations, sounds, and photographs highlighting Myanmar's cultural legacy in a digital format. Along with virtual content, Leap Motion provided navigational elements such as virtual buttons and touch-based hand gestures. As a result, the produced iSAR book enabled the seamless integration of virtual material and navigational functions into a physical book. Five participants were chosen to review the prototype iSAR book, and interviews were performed to elicit their opinions regarding the book's immersive aspects. Thus, the produced iSAR book on Myanmar efficiently communicates the nation's cultural history, allowing users to explore and better understand the country.

Desierto [56] intends to incorporate augmented reality (AR) technology into storytelling to enrich and motivate children's reading experiences. The primary purpose of this project was to create GoonAR, a multilingual augmented reality children's storybook smartphone application. GoonAR is a smartphone application for Android that uses augmented reality technology to depict 3D characters and locations in the tale. The software provides an enjoyable learning experience for auditory, kinaesthetic, and visual learners while immersing them in educational activities. A unique story was constructed, as well as a pseudo-book. The pseudo-book makes use of augmented reality technologies to display 3D assets. Grade 1 pupils under the age of 6-7 years old are the intended users of this programme, as this is the age at which children begin to learn to read. The users may comprehend the tale in two ways: (1) with the assistance of a narrator who speaks both English and Filipino, or (2) by reading it on their phone and watching displayed 3D objects made possible by the usage of Unity and the Vuforia framework.

Huang [57] utilises both the story and the three-dimensional, tactile qualities of pop-up books to engage audiences with digital material via augmented reality. The paper's technological contributions included enabling real-time interaction between the book's physical features and its virtual content. Unlike previous augmented reality pop-up books, Huang's design retains the original 3D model. It provides virtual effects on those things, making the application more appealing and engaging than other augmented reality pop-up books. This concept and technological method are implemented using a commercially available pop-up book containing narratives about numerous iconic London sites. Incorporating visual information and interactivity from historical collections enhances the narrative recounted in the book. Initial studies indicate that this strategy can engage viewers who are not accustomed to accessing other sites with $\mathrm{CH}$ material.

Additionally, Red Frog Digital Limited produced iDinosaur; it is an Android app that functions in conjunction with the iDinosaur book. With the iDinosaur book, the programme requires a rear-facing camera to unleash augmented reality dinosaurs. Each page features photographs of various dinosaurs. To view the dinosaur animations in action, the user must locate the yellow augmented reality boxes that serve as markers for the realistic 3D model dinosaur. Users may now witness the dinosaurs come to life by launching the app and directing their device's camera at the book when it is open flat on the floor or table. These dinosaurs are contained within crates, which the user must press to liberate the dinosaur and allow it to wander freely. Users may rotate their mobile devices 360 degrees to obtain a complete look at each dinosaur.

Additionally, kids may control the dinosaur through the on-screen joystick. Users may make dinosaurs scream or carefully reintroduce them to their boxes with a single press. Users may take self-portraits with each dinosaur, printed or shared.

Sara [58] introduced users to a new and unique method of comprehending and appreciating art. When people admire artworks, their sensations and emotions are heightened due to the sensory integration of the AR contents and olfactory cues. Additionally, utilising augmented reality and olfactory devices to elicit visual and olfactory encounters enhances the likelihood of users forming long-lasting memories. Indeed, scent plays a 
critical role in creating and retrieving emotional memories, owing to the olfactory cortex's direct connection to the limbic system.

Most of the above works have made significant contributions to the implementation of AR techniques in educational methods, focusing on AR books and evaluating new ways of combining education and entertainment for the students. However, research on collaborative learning experiences appears limited, even though it can be enhanced using modern technologies, which immerse multiple users in a digital environment with extended learning capabilities. Integrating AR methods in collaborative education is a field that has not been exploited sufficiently yet. This work focuses on evaluating AR, digital storytelling, and personalisation methods in this research field.

\section{Methodological Approach}

This section is divided into subheadings, providing a concise and precise description of the AR book architecture, the AR book prototype, and the AR book user personas and use case scenarios.

\subsection{AR Book Architecture}

The object of the system architecture is the analysis and mapping of the software components required to realise the use scenarios. In addition, the architecture reflects the interoperability of software components.

Software systems contain thousands of lines of code, tables and database elements that all work on one or more servers. These present some challenges for software development teams. If these challenges are not addressed early, systems deliver slowly, at a high cost or with an unacceptably low level of quality.

To understand a complex software system, such as the augmented reality application for the AR book, we need to understand what each of its building blocks really does, how they work together and how they interact with each other and with end-users, in other words, to capture the software's architectural solution.

The architecture of a system is a metaphor analogous to the architecture of a building. It acts as a blueprint for the design and the growing project, defining the tasks necessary for the execution by the planning and development teams.

The result of this activity will be the overall architecture of the system, its distribution into functional modules and components, with detailed specifications for each of them, including operational and operational requirements, and details about software interactions and interfaces. Architecture should address diversity in equipment (hardware and software) and allow for future changes, updates and upgrades. This activity will identify the general methodologies, technologies and standards that will form the basis for the technical and scientific work to be carried out during the development of the system.

Software architecture describes the system from the perspective of the software components, their connections and their exchange data. In essence, architecture is a design of building blocks that meet clearly defined requirements and, by extension, systems that have the characteristics required to meet user requirements.

The main challenge of architecture is the interoperability of the building blocks, tools and services available to users of the environment with the ultimate goal to secure data sharing and functionality. Most of the identified use cases focus on data control and entry. To meet the requirements imposed by these use cases, a scalable and flexible environment capable of effectively integrating all components is required. Web/REST (Representational State Transfer) service technologies, which have gained momentum in recent years, are adopted by the platform for communication between its data. At the same time, an authorisation/authentication server validates all actions.

The system has been designed based on a multi-level architecture (security level, data level, tool layer and interface level). Each item/service can be assigned to one of these levels or extended to multiple levels. Modules and components designed and constructed should 
operate seamlessly through well-defined interfaces at different levels (i.e., interoperability at the level of protocol, data format, information content, etc.) (Figure 2).

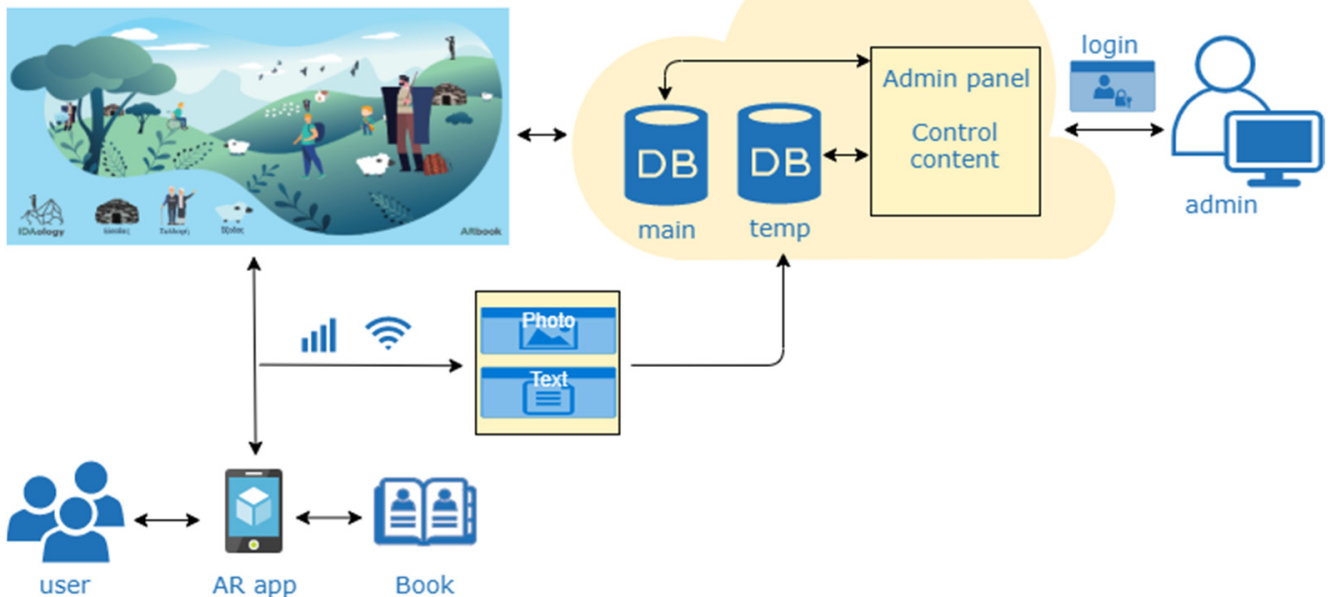

Figure 2. AR book architecture.

\subsection{AR Book Prototype}

There are many tools for developing augmented reality applications. After research conducted on selecting the appropriate tools, we concluded that Unity3D, in combination with the addition of Vuforia, is quite effective for the development of augmented reality applications, resulting in the AR book application.

Unity3D is a platform primarily used to develop two- or three-dimensional games and simulations. This software is mainly used in virtual, mixed and augmented reality applications to create interactive experiences of various content. Vuforia is a software package that is installed on the above platform and allows the creation of AR applications; that is, it is practically a library with functions that mainly concern the detection of objects, thus having a better response and adaptation of the digital content to the physical object (Figure 3).
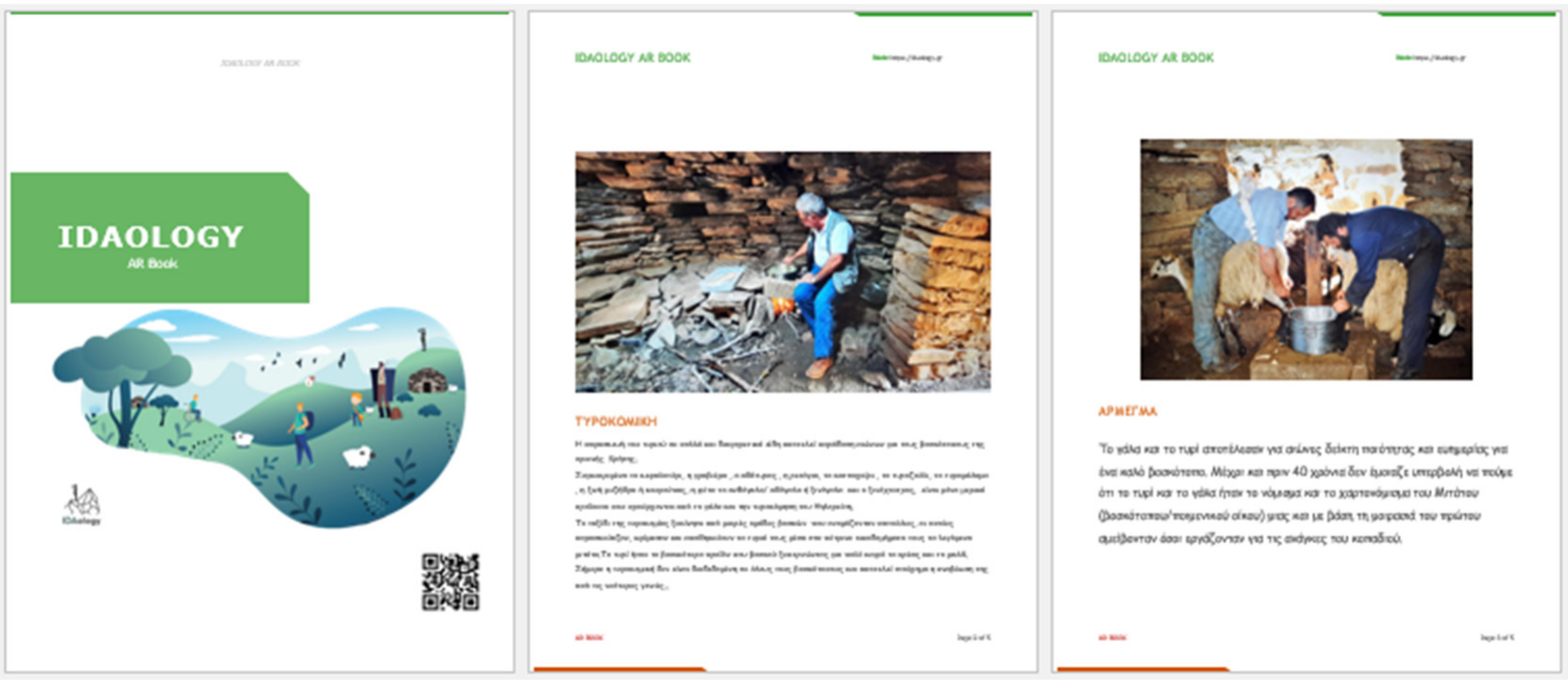

Figure 3. Physical book. 
After installing the application and accepting the needed licences, the user can use it. Then, when activating the application, they can select from a menu of several characters that will assist them in comprehending the text. By rotating the camera and scanning the pages of the augmented reality book, scenes and heroes from the mountain's history will come to life. The user is given the option of creating their own material or adding previously created information related to the topic of each tale, contributing to the exchange of knowledge and know-how with locations that have equivalent intangible cultural heritage aspects. This supports the addition of a text and picture file. A computer with an internet connection is required for this. After verifying with the administrator, the file determines if it fits the eligibility standards for inclusion in the application and visibility to other users. Finally, the application's user can be photographed with their favourite character (Figure 4).
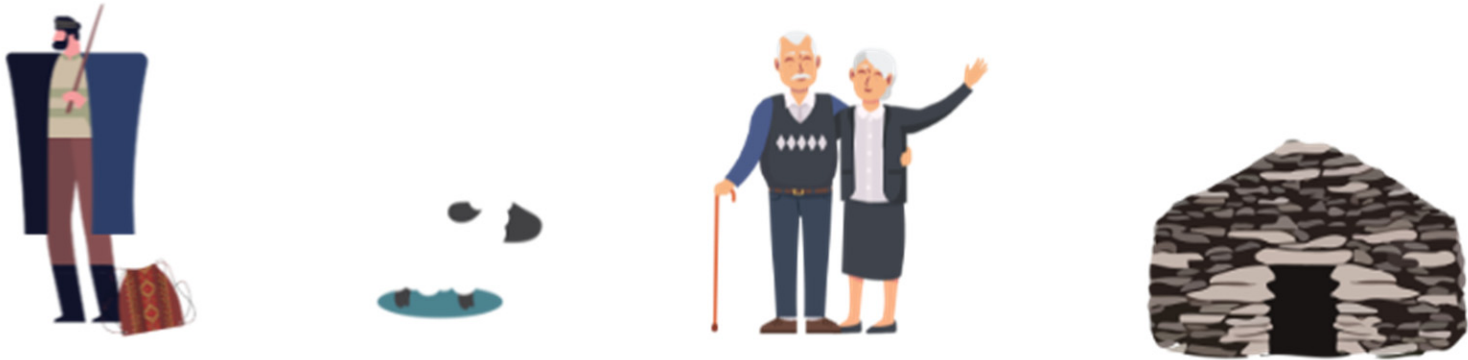

Figure 4. AR book characters-user personas.

The AR book app is part of the software available for installation on users' mobile devices through the official software repositories (Google Play Store, Apple App Store).

The application management environment will be installed on a deployment server and available via a network to administrators. Figure 5 shows the installation diagram of the individual software components.

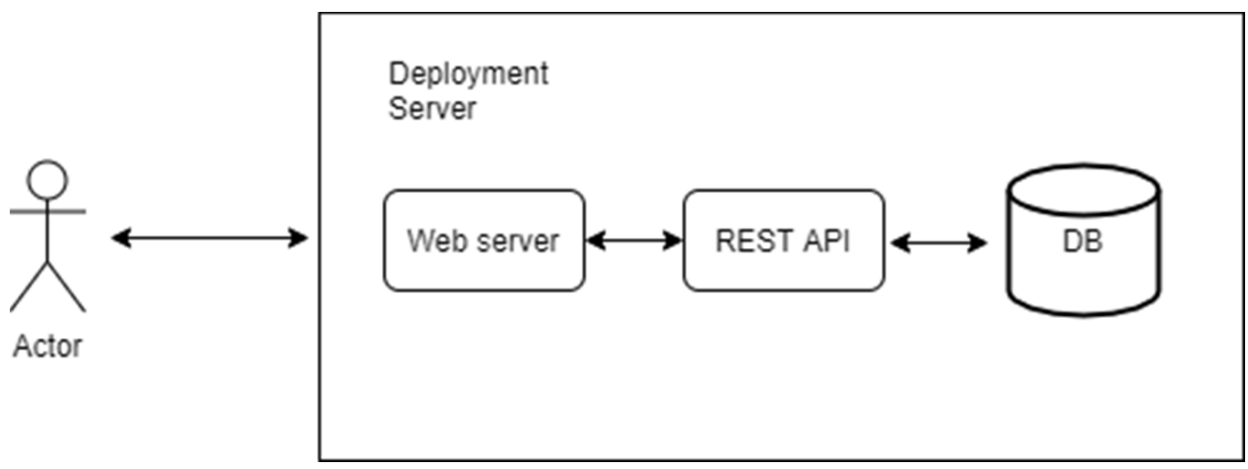

Figure 5. Installation diagram of the individual software components.

\subsection{AR Book User Groups}

Administrator: The administrator is responsible for the correct operation of the application for smart mobile devices, having access to the different levels of the system architecture. Administrators are required to ensure the proper functioning of the system and process system performance reports. The role of the administrator is supportive and concerns the technical level of systems and applications.

The administrator has full access and processing rights and can import, edit, delete, search/retrieve all the information (textual and visual) that appears in the application and concerns the pastoral life of Psiloritis. In addition, they are the only end-to-end internal user who has the maximum content management permissions for all information fields. Therefore, they have general oversight of the content that can be imported.

External end-users: External end-users are all users interested in knowing the livestock cultural heritage at the Psiloritis geopark. Users who may be adult citizens of Greece or 
abroad, children or students who, with the help of the book in combination with the use of intelligent portable devices and a special AR application, will be able to bring to life scenes, heroes, and traditions from a mountain with its shepherd as the timeless protagonist.

The end external user has access to the published material (text, videos, images, links to applications). With the launch of the application, the user will be able to choose from different characters who will narrate the traditions of the mountain and help them understand the book. The user will also be able to be photographed with their favourite character.

At the same time, the user will be allowed to add content to the application related to the book's subject. The content can be in the form of text and photo files. Upon request to the administrators, they will be able to request the processing or deletion of all the information (textual and visual) that they have added.

\subsection{Three-Dimensional Models of AR Children's Book}

For the implementation of the 3D models required in the AR children's book, the Cinema4D software was used. The 3D models were constructed in accordance with the size requirements, which allows the AR application to run smoothly. Furthermore, the 3D objects appearing in the AR feature are closely related to the physical book's actual figures (Figures 6-8).

\subsection{Use Case Scenarios}

Scenario 1: Installation and application operation

In this scenario, the user will be informed how they can install the app by scanning the QR code at the beginning of the book or by downloading for free from Google Play or the Apple Store. Then we will see how the user opens the application and chooses one of the heroes that will help them to understand the book.

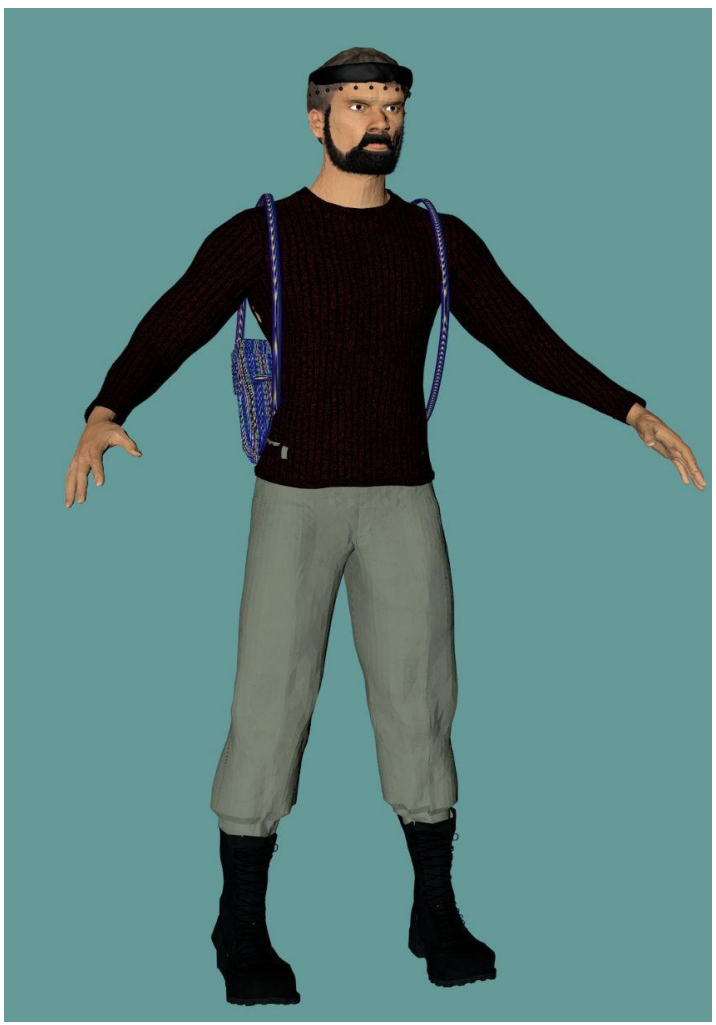

Figure 6. The 3D model of a shepherd from Crete. 


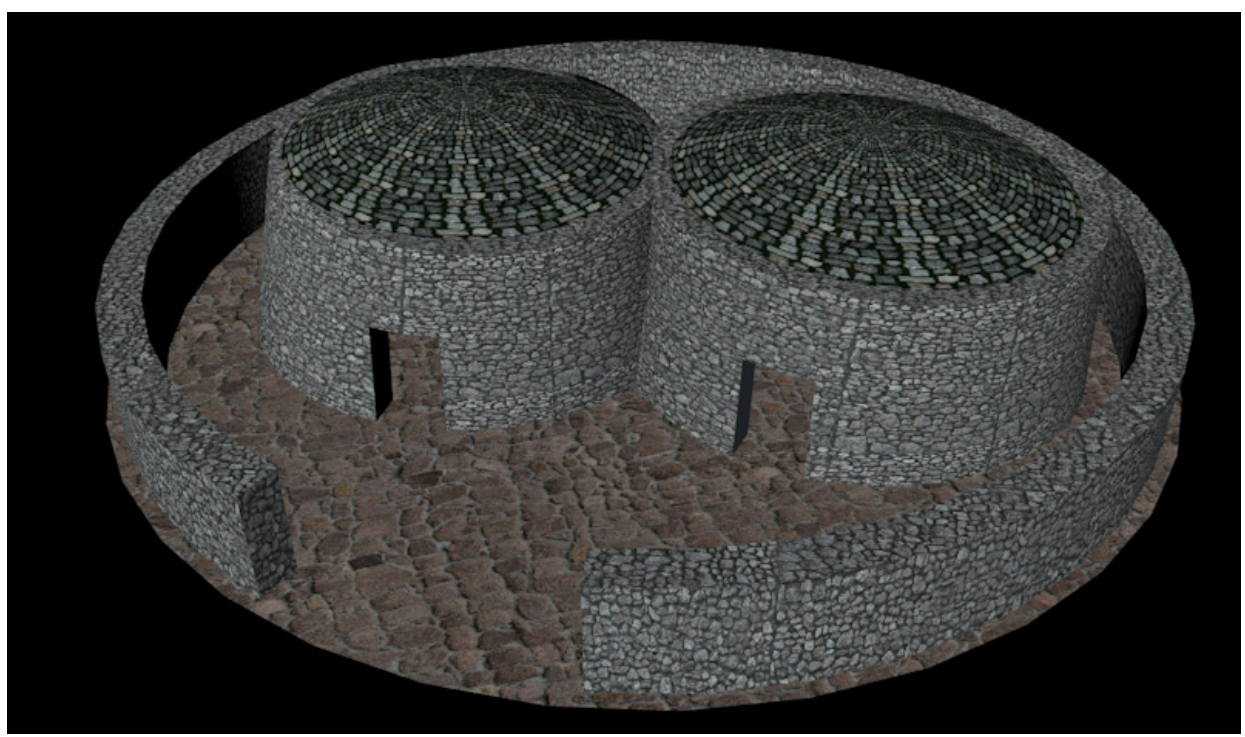

Figure 7. The 3D model of sheep shed.
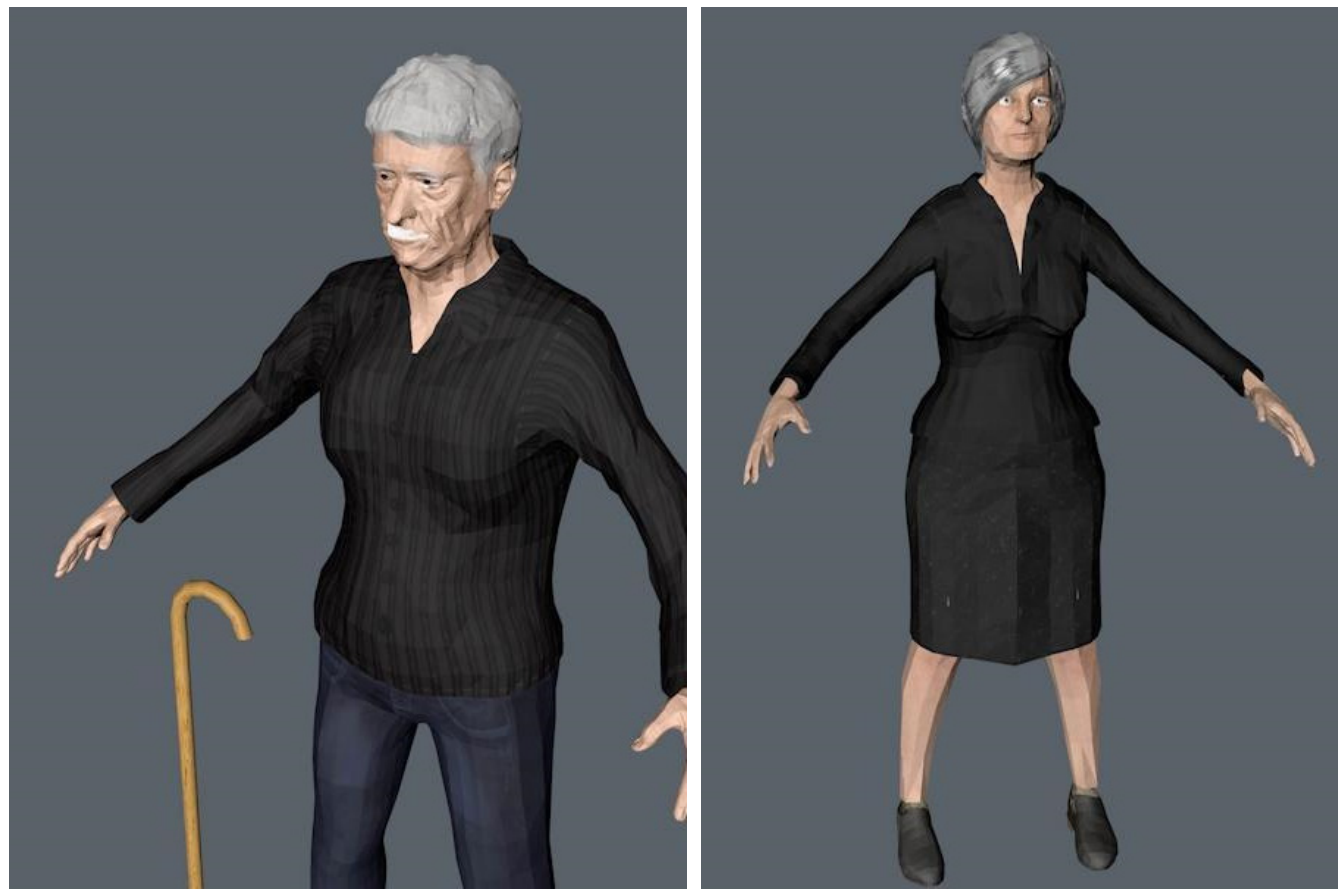

Figure 8. The 3D models of an old couple.

The user installs the application by scanning the QR code in the AR book. The user starts the application and selects one of the different characters. Then, scanning the book's pages with the mobile phone, the selected hero will appear on each page, telling stories and traditions from a mountain with his shepherd as the protagonist. With both fingers, they will be able to resize the heroes, while being able to move them with one finger. By completing the story's presentation, they will be able to watch the content that other users have added. Finally, by pressing the camera button located in the options' menu of the application, the user will be able to take pictures along with the hero of each page.

Scenario 2: To add, modify, or delete a file

This scenario will describe how the user will add content to the AR book app.

The application is installed by scanning the QR code located in the AR book or downloading it for free from Google Play or the Apple Store. After initiating the application's 
launch, the user will be taken to the application's primary menu of choices. They can contribute content to the application pertaining to the book's subject via the menu. By selecting this option and hitting the "Add content" button, the form for adding and describing the file is displayed. The user completes the required forms and selects the file to upload, which can be in either text or picture format. To finish the procedure, the user must agree to the General Data Protection Regulation (GDPR), understanding that they may remove any files added for any reason by contacting the administrator (Figure 9).

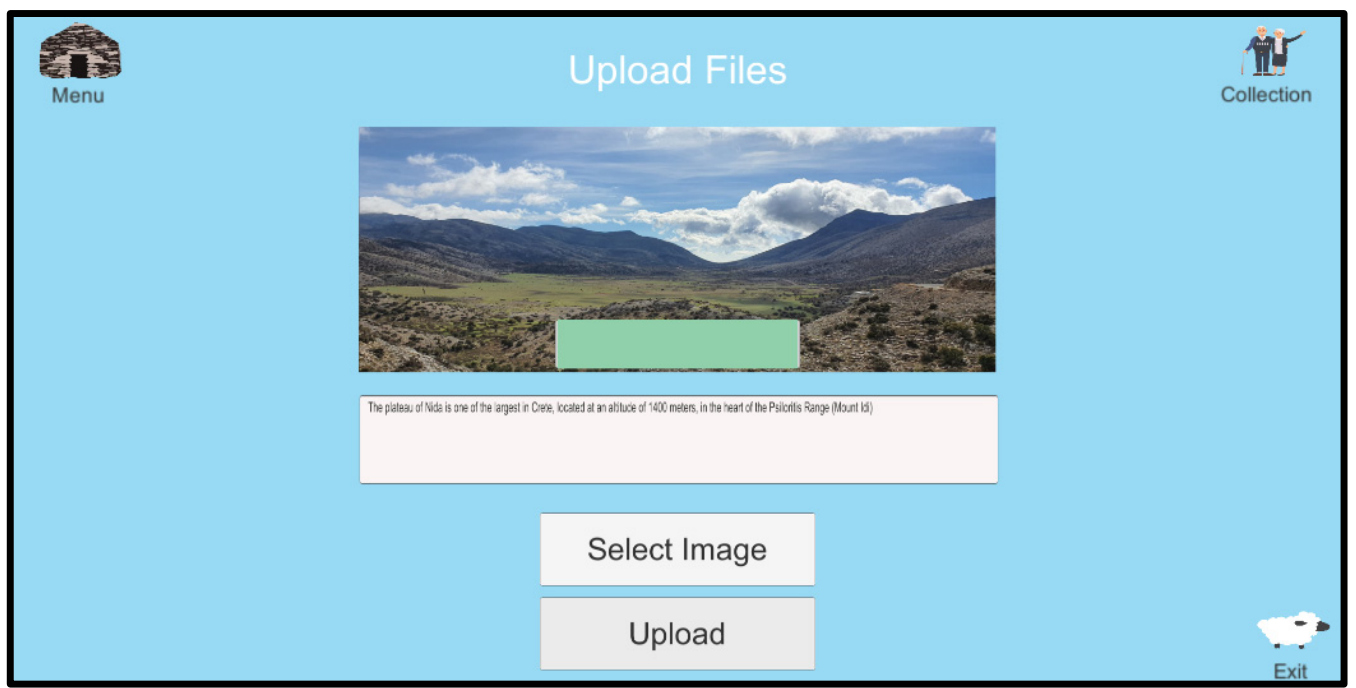

Figure 9. Scenario 2: To add, modify or delete a File.

Scenario 3: Add new content and check uploaded files to add to the AR Book app. This scenario will describe how the administrator controls the content users add or how they can add content visible to the end-user.

The administrator is appointed the person responsible for the correct operation of the application having access to the different levels of the system architecture. Administrators are required to ensure the proper functioning of the system and process system performance reports. The role of the administrator is supportive and concerns the technical level of systems and applications. The app administrator can add, modify, or delete content to the end-user. They will be able to add new files if it is deemed appropriate for the files sent by the users to be published (Figure 10).

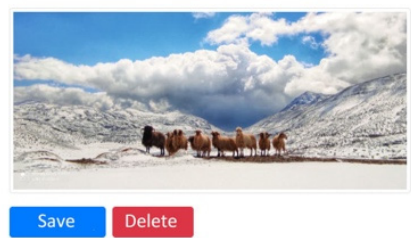

File name : 1616755449884 (1)-01.jpeg

Upload Date : 22-07-2021, 15:37

Descpription: Sheep - Nida Plateau

$\square$ Accepted

Figure 10. Scenario 3: Add new content and check uploaded files to add to the AR book app.

The administrator uses the application from their computer or mobile phone/tablet and enters the system with their credentials. The form for creating a file or approving the uploaded files by users appears, in which it will be possible to select one or more files. To create new content, they choose the creation section. The mandatory file description fields are opened, they select the file and add it. They can then check the suitability of the files added by users and accordingly decide, based on specific criteria, whether they 
can be published. They fill in all the necessary fields for the description and category of files, press add or approve, respectively, to display the file selection window. Selecting the corresponding file adds it to the application. Once the process is completed, the system returns a message of success.

\section{Evaluation}

One of the essential stages during the implementation of an application is its evaluation by the users themselves. The conclusions that come out about the user experience are very important, and a proper reading of the results helps the developers to optimise the performance of the application. Questionnaires, interviews and user observations, as stated earlier, are the most widely known ways of evaluation.

A questionnaire was created for the AR book application that can cover a wide range of users and functions. An anonymous questionnaire means that each user can evaluate the augmented reality prototype application. The questions are structured to evaluate the usability and effectiveness of the original, whether the level of interaction affects the performance of users and, finally, the balance between augmented reality, content personalisation and digital storytelling in mobile applications with intangible cultural heritage content.

For the purpose of the evaluation, end-users were asked to test the application; experts observed their reactions during the process and the interaction with the application. Then, the users answered the questionnaire. Users either participated in groups (school class) or individually. A total of 50 users (20 men, 30 women) participated in the evaluation, including 30 children and 20 adults. All users had no previous experience with augmented reality applications, but all were familiar with digital technologies (Figures 11-13).

Participants had $20 \mathrm{~min}$ to use the mobile application according to their instructions. They then participated for $10 \mathrm{~min}$ in a comparative assessment: using an AR book versus a traditional book.

In the end, a questionnaire (see responses in Figures 14-16) was filled out by the adults. At the same time, the children performed a short interview to evaluate their experience during the application's use.

Based on [59], which provides very relevant conclusions about the perceptions that teachers have about the use of augmented reality in educational contexts, the most important findings were that the interaction in the classroom with augmented reality experiences promotes new teaching-learning methodologies and favours technological skills related to the use of ICT. Moreover, the strategies designed for the benefit of AR and other technologies positively influence the information processing capacities of students. At the same time, new tasks are proposed that motivate and allow the achievement of the objectives proposed in the classroom. The use of augmented reality facilitates and increases the educational use of the itineraries both in school outings, museums, exhibitions, etc., as within the classroom itself. Its use in simulations allows, at least in the initial phases of learning, exciting features such as ease, availability, immediacy, safety in practice, learning by trial and error, cost reduction, etc. AR allows us to "manipulate" with our hands from a sculpture to a painting, passing through a plant, a dinosaur, a building, etc., a whole world within reach of a camera.

Therefore, by collecting and analysing the answers, we came up with the following:

- The majority of participants believed that it was a positive educational experience during which they learnt new information about Psiloritis' pastoral life.

- On a scale of 1 to 5, consumers scored the augmented reality app a 4 for its ability to entice them to continue using it after two minutes.

- The majority of participants expressed a desire for a connection via social media while stating that the interactive content production process aided in promoting cultural heritage. 
- Some players considered the methods relatively simple and requested that a comprehensive version be created that included a scoring game in which users may join teams.

- All twenty people agreed on the educational value of applying it to their children and introducing them to Psiloritis' pastoral life via current digital technology.

- The majority of them stated that the application and book help preserve and promote intangible cultural assets.

- The youngsters were ecstatic and stated that they, too, would want textbooks to be created in this manner.

- Everyone agreed that the AR's content captures children's interest and entices them to continue reading the narrative.

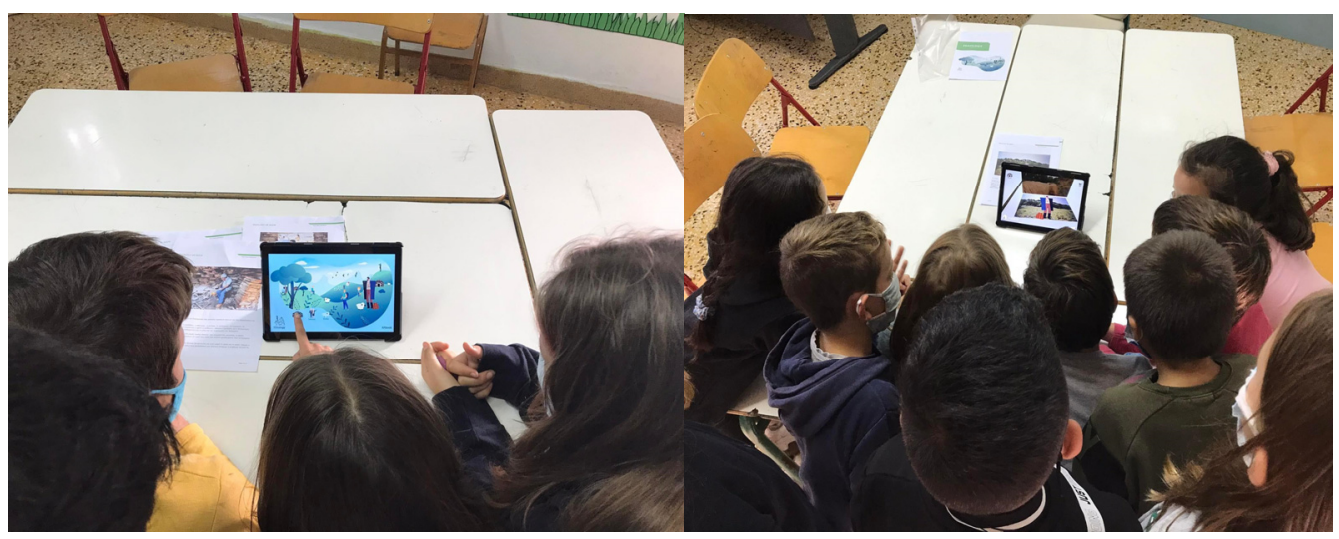

Figure 11. School class evaluation-user observation procedure.

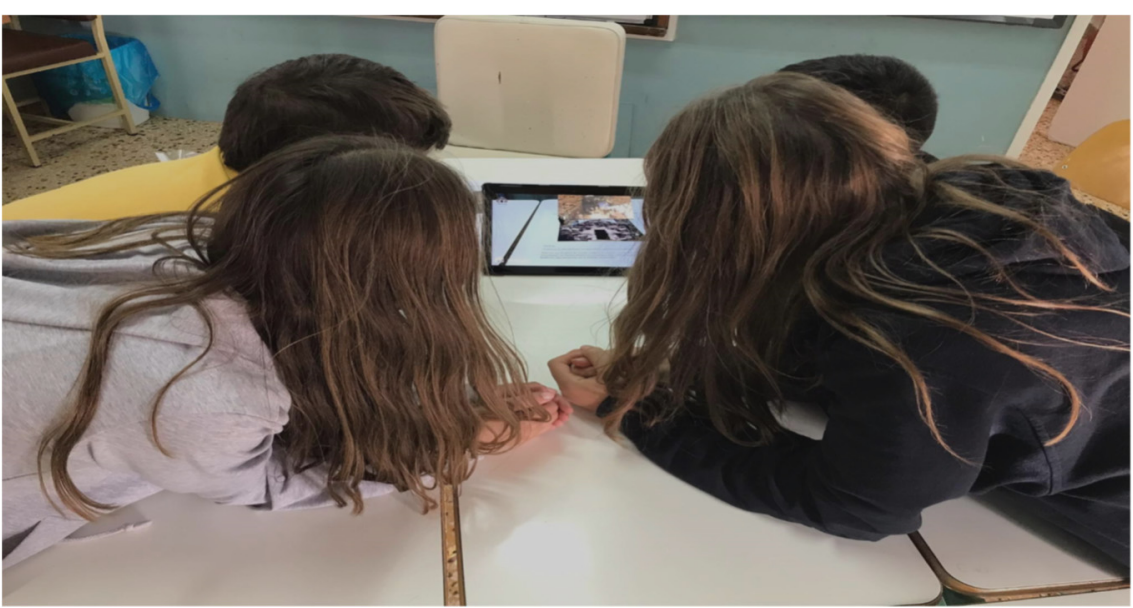

Figure 12. School class evaluation-user observation procedure.

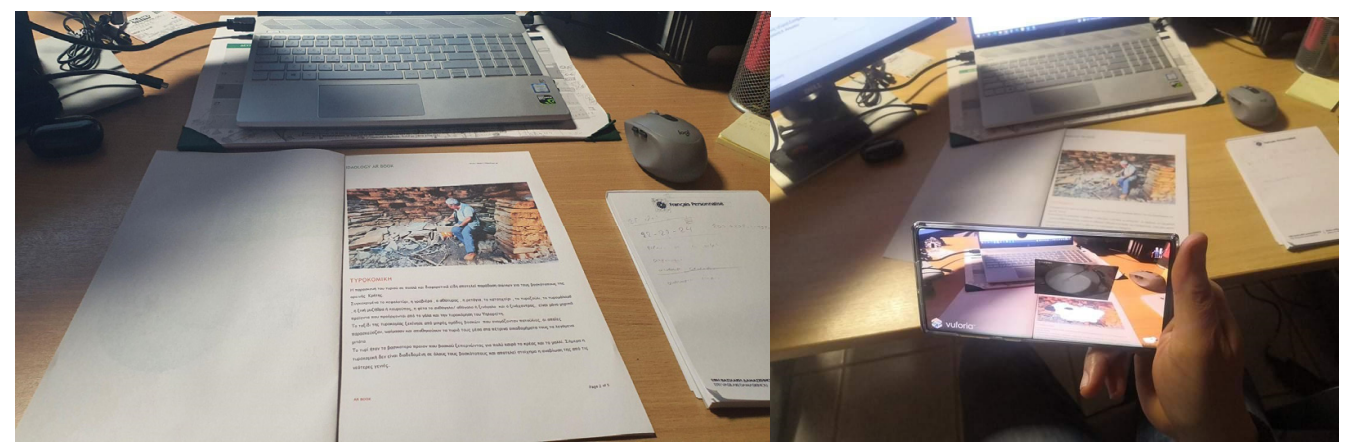

Figure 13. AR book versus a traditional book. 


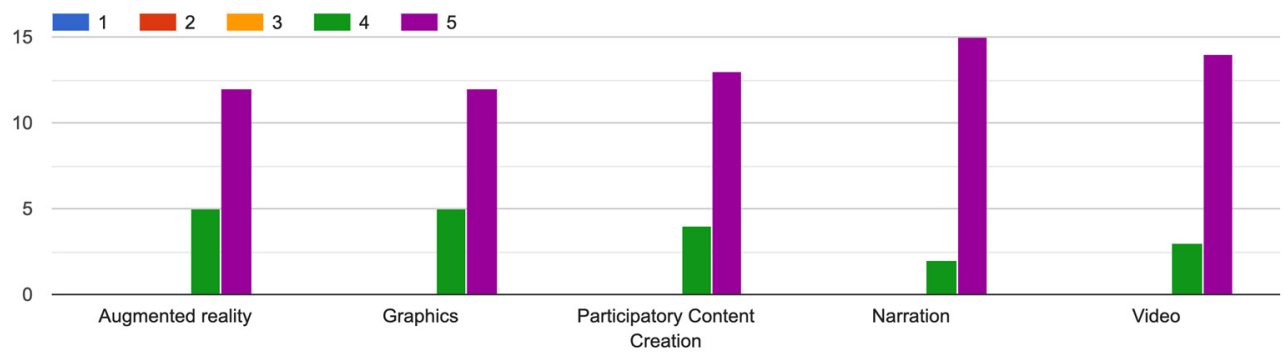

Figure 14. Questionnaire responses during the evaluation phase.

Which is your knowledge level about pastoral life of psiloritis

17 responses

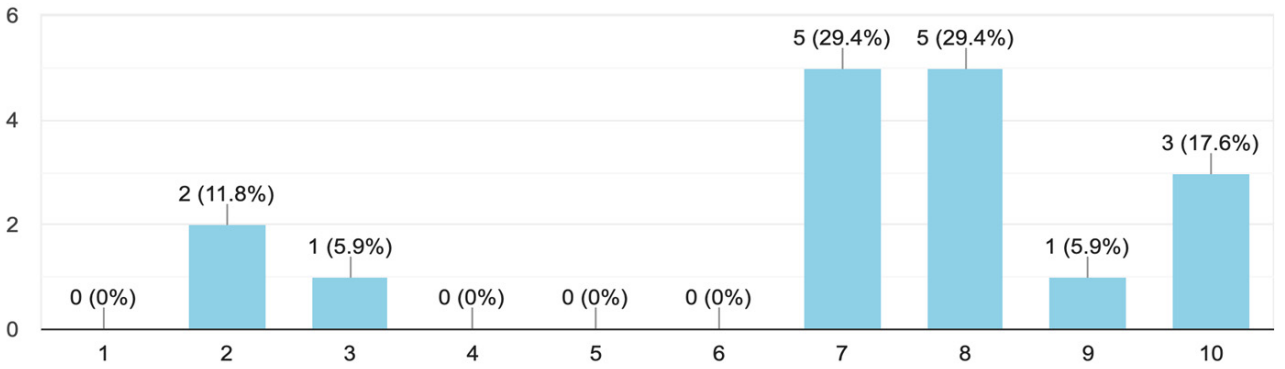

Figure 15. Questionnaire responses during the evaluation phase.

The Participatory Content Creation contribute to the promotion of cultural heritage? 18 responses

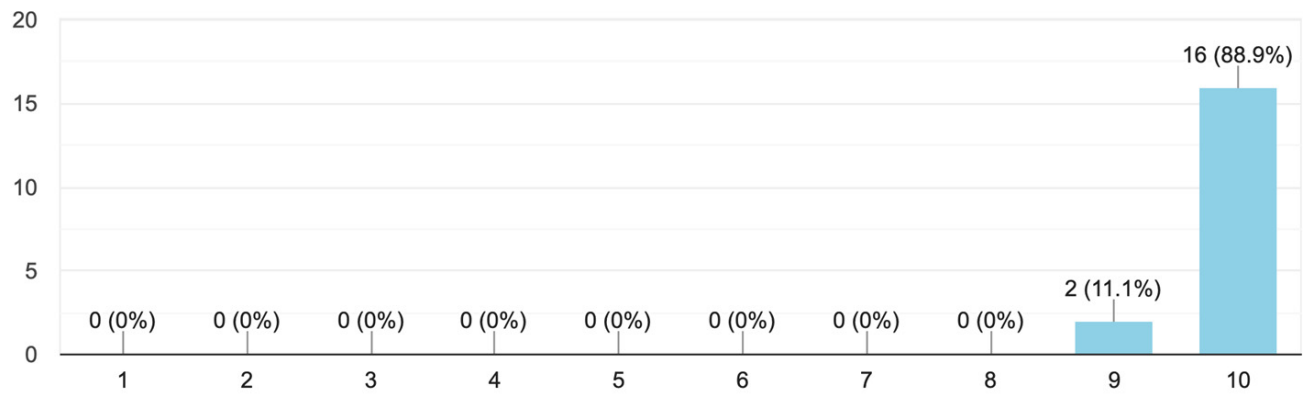

Figure 16. Questionnaire responses during the evaluation phase.

\section{Conclusions}

The current article discusses using an intangible book as a teaching tool to enhance collaborative learning experiences in school education through modern technologies (augmented reality, digital storytelling, and personalisation) by fusing learning and fun in an immersive environment. This entertaining method boosts motivation to study and stimulates interest in art history and cultural heritage associated with Psiloritis' pastoral lifestyle.

While some progress has been made in edutainment through participatory content creation and promotion, there is still a shortage of research and unanswered questions about how augmented reality can be integrated into educational curricula at various learning stages and how it affects multiple aspects of learning, such as collaboration and content creation. In this regard, our research fills a void by examining the collaborative experience of primary school kids as they interact with an augmented reality book. Additionally, it aims to demonstrate how augmented reality may be created for these specific consumers, providing new directions for developing augmented reality books through a collaborative content creation and promotion method for and with children. 
Future studies can provide further light on how deeply youngsters can comprehend the message of an AR book and on the design principles that should guide the development of effective AR books. Additionally, a future research direction would be to develop the application in both the Android and iOS environments and enrich the user and item profile representations by using additional information sources such as ontologies, the semantic web or more individualised information. Additionally, to boost a potential visitor's prior awareness and willingness/motivation to visit a cultural destination such as the mountain of Psiloritis, popular social media applications might promote the attraction's culture and heritage before the actual visit.

Author Contributions: Conceptualization, A.N. and M.K.; methodology, M.K.; software, M.K. and D.M.; validation, D.M., M.K. and J.A.; formal analysis, A.N.; investigation, A.N.; resources, D.M. and L.K.; data curation, M.K.; writing — original draft preparation, M.K.; writing-review and editing, D.M. and L.K.; visualisation, J.A.; supervision, M.K., G.C.; project administration, A.N., G.C.; funding acquisition, A.N. All authors have read and agreed to the published version of the manuscript.

Funding: This research has been co-financed by the European Regional Development Fund of the European Union and Greek national funds through the Operational Program Competitiveness, Entrepreneurship, and Innovation, under RESEARCH-CREATE-INNOVATE (project code: T1EDK03995-IDAology).

Institutional Review Board Statement: Not applicable.

Informed Consent Statement: Not applicable.

Conflicts of Interest: The authors declare no conflict of interest.

\section{References}

1. Phon, D.N.E.; Ali, M.B.; Halim, N.D.A. Collaborative augmented reality in education: A review. In Proceedings of the 2014 International Conference on Teaching and Learning in Computing and Engineering, Kuching, Malaysia, 11-13 April 2014; IEEE: Piscataway, NJ, USA, 2014; pp. 78-83.

2. Di Serio, Á.; Ibáñez, M.B.; Kloos, C.D. Impact of an augmented reality system on students' motivation for a visual art course. Comput. Educ. 2013, 68, 586-596. [CrossRef]

3. Kreijns, K.; Van Acker, F.; Vermeulen, M.; Van Buuren, H. What stimulates teachers to integrate ICT in their pedagogical practices? The use of digital learning materials in education. Comput. Hum. Behav. 2013, 29, 217-225. [CrossRef]

4. Ntagiantas, A.; Manousos, D.; Konstantakis, M.; Aliprantis, J.; Caridakis, G. Augmented Reality children's book for intangible cultural heritage through participatory content creation and promotion. Case study: The pastoral life of Psiloritis as a UNESCO World Geopark. In Proceedings of the 2021 16th International Workshop on Semantic and Social Media Adaptation \& Personalization (SMAP), Corfu, Greece, 4-5 November 2021; IEEE: Piscataway, NJ, USA, 2021; pp. 1-4.

5. Khan, A.; Khusro, S.; Rauf, A.; Mahfooz, S. Rebirth of augmented reality-enhancing reality via smartphones. Bahria Univ. J. Inf. Commun. Technol. 2015, 8, 110 .

6. Barfield, W. Fundamentals of Wearable Computers and Augmented Reality; CRC Press: Boca Raton, FL, USA, 2015.

7. Ibáñez, M.B.; Di Serio, A.; Villarán, D.; Delgado-Kloos, C. The acceptance of learning augmented reality environments: A case study. In Proceedings of the 2016 IEEE 16th International Conference on Advanced Learning Technologies (ICALT), Austin, TX, USA, 25-28 July 2016; IEEE: Piscataway, NJ, USA, 2016; pp. 307-311.

8. Tom Dieck, M.C.; Jung, T. A theoretical model of mobile augmented reality acceptance in urban heritage tourism. Curr. Issues Tour. 2018, 21, 154-174. [CrossRef]

9. Cranmer, E.; Jung, T.; tom Dieck, M.C.; Miller, A. Understanding the acceptance of augmented reality at an organisational level: The case of Geevor Tin Mine Museum. In Information and Communication Technologies in Tourism 2016, Proceedings of the International Conference, Bilbao, Spain, 2-5 February 2016; Springer: Cham, Switzerland, 2016; pp. 637-650.

10. Rese, A.; Baier, D.; Geyer-Schulz, A.; Schreiber, S. How augmented reality apps are accepted by consumers: A comparative analysis using scales and opinions. Technol. Forecast. Soc. Chang. 2017, 124, 306-319. [CrossRef]

11. Chang, Y.L.; Hou, H.T.; Pan, C.Y.; Sung, Y.T.; Chang, K.E. Apply an augmented reality in a mobile guidance to increase sense of place for heritage places. J. Educ. Technol. Soc. 2015, 18, 166-178.

12. Attila, K.; Edit, B. Beyond reality: The possibilities of augmented reality in cultural and heritage tourism. In Proceedings of the 2nd International Tourism and Sport Management Conference, Debrecen, Hungary, 22-24 September 2012; Volume 5.

13. Lukosch, S.; Billinghurst, M.; Alem, L.; Kiyokawa, K. Collaboration in augmented reality. Comput. Supported Coop. Work 2015, 24, 515-525. [CrossRef]

14. Fenu, C.; Pittarello, F. Svevo tour: The design and the experimentation of an augmented reality application for engaging visitors of a literary museum. Int. J. Hum.-Comput. Stud. 2018, 114, 20-35. [CrossRef] 
15. Spierling, U.; Winzer, P.; Massarczyk, E. Experiencing the presence of historical stories with location-based augmented reality. In Interactive Storytelling, Proceedings of the International Conference on Interactive Digital Storytelling, Funchal, Portugal, 14-17 November 2017; Springer: Cham, Switzerland, 2017; pp. 49-62.

16. Trichopoulos, G.; Aliprantis, J.; Konstantakis, M.; Caridakis, G. Artists: A Virtual Reality Cultural Experience Personalized Artworks System: The "Children Concert" Painting Case Study. In Proceedings of the International Conference on Digital Culture \& AudioVisual Challenges, Corfu, Greece, 1-2 June 2018.

17. Clarizia, F.; Colace, F.; Lombardi, M.; Pascale, F. A context aware recommender system for digital storytelling. In Proceedings of the 2018 IEEE 32nd International Conference on Advanced Information Networking and Applications (AINA), Krakow, Poland, 16-18 May 2018; IEEE: Piscataway, NJ, USA, 2018; pp. 542-549.

18. Pujol, L.; Katifori, A.; Vayanou, M.; Roussou, M.; Karvounis, M.; Kyriakidi, M.; Ioannidis, Y. From personalization to adaptivityCreating immersive visits through interactive digital storytelling at the Acropolis Museum. In Workshop Proceedings of the 9th International Conference on Intelligent Environments; IOS Press: Amsterdam, The Netherlands, 2013; pp. 541-554.

19. Pietroni, E.; Ferdani, D.; Palombini, A.; Forlani, M.; Rufa, C. Lucus Feroniae and Tiber Valley Virtual Museum: From Documentation and 3d Reconstruction, Up to a Novel Approach in Storytelling, Combining Virtual Reality, Theatrical and Cinematographic Rules, Gesture-based Interaction and Augmented Perception of the Archaeological Context. In Proceedings of the CAA2015, Siena, Italy, 30 March-3 April 2016; Volume 1, p. 67.

20. Konstantakis, M.; Alexandridis, G.; Caridakis, G. A personalized heritage-oriented recommender system based on extended cultural tourist typologies. Big Data Cogn. Comput. 2020, 4, 12. [CrossRef]

21. Trichopoulos, G.; Aliprantis, J.; Konstantakis, M.; Michalakis, K.; Mylonas, P.; Voutos, Y.; Caridakis, G. Augmented and personalized digital narratives for Cultural Heritage under a tangible interface. In Proceedings of the 2021 16th International Workshop on Semantic and Social Media Adaptation \& Personalization (SMAP), Corfu, Greece, 4-5 November 2021; IEEE: Piscataway, NJ, USA, 2021; pp. 1-5.

22. Kanoje, S.; Girase, S.; Mukhopadhyay, D. User profiling trends, techniques and applications. arXiv 2015, arXiv:1503.07474.

23. Sobhanam, H.; Mariappan, A.K. Addressing cold start problem in recommender systems using association rules and clustering technique. In Proceedings of the 2013 International Conference on Computer Communication and Informatics, Coimbatore, India, 4-6 January 2013; IEEE: Piscataway, NJ, USA, 2013; pp. 1-5.

24. Wolfe, S.R.; Zhang, Y. Interaction and personalization of criteria in recommender systems. In Proceedings of the International Conference on User Modeling, Adaptation, and Personalization, Manoa, HI, USA, 20-24 June 2010; Springer: Berlin/Heidelberg, Germany, 2010; pp. 183-194.

25. Christodoulou, Y.; Konstantakis, M.; Moraitou, E.; Aliprantis, J.; Caridakis, G. Personalized Cultural Tours using Semantic Web Technologies. In Proceedings of the SMAP2019 Workshop, Larnaca, Cyprus, 9-10 June 2019.

26. Wang, J.; Pouwelse, J.; Fokker, J.; de Vries, A.P.; Reinders, M.J. Personalization on a peer-to-peer television system. Multimed. Tools Appl. 2008, 36, 89-113. [CrossRef]

27. Hameed, M.A.; Ramachandram, S.; Al Jadaan, O. Information Gain Clustering through Prototype-Embedded Genetic K-Mean Algorithm (IGCPGKA) a novel heuristic approach for personalisation of cold start problem. In Proceedings of the Second International Conference on Computational Science, Engineering and Information Technology, Coimbatore, India, 26-28 October 2012; pp. 390-395.

28. Mac Aoidh, E.; Bertolotto, M.; Wilson, D.C. Towards dynamic behavior-based profiling for reducing spatial information overload in map browsing activity. Geoinformatica 2012, 16, 409-434. [CrossRef]

29. Bonis, B.; Stamos, J.; Vosinakis, S.; Andreou, I.; Panayiotopoulos, T. A platform for virtual museums with personalized content. Multimed. Tools Appl. 2009, 42, 139-159. [CrossRef]

30. Antoniou, A.; Lepouras, G. Modeling visitors' profiles: A study to investigate adaptation aspects for museum learning technologies. J. Comput. Cult. Herit. 2010, 3, 1-19. [CrossRef]

31. Antoniou, A. Social network profiling for cultural heritage: Combining data from direct and indirect approaches. Soc. Netw. Anal. Min. 2017, 7, 1-11. [CrossRef]

32. Paliokas, I.; Sylaiou, S. The use of serious games in museum visits and exhibitions: A systematic mapping study. In Proceedings of the 2016 8th International Conference on Games and Virtual Worlds for Serious Applications (VS-GAMES), Barcelona, Spain, 7-9 September 2016; IEEE: Piscataway, VJ, USA, 2016; pp. 1-8.

33. Kalatha, E.; Aliprantis, J.; Konstantakis, M.; Michalakis, K.; Moraitou, T.; Caridakis, G. Cultural Heritage engagement via Serious Games: The ARCADE Augmented Reality, Context Aware, linked open Data pErsonalized ecosystem. In Proceedings of the 1st International CICMS Conference, Kuşadası, Turkey, 4-5 May 2018; p. 309.

34. Konstantakis, M.; Kalatha, E.; Caridakis, G. Cultural Heritage, Serious Games and User Personas Based on Gardner's Theory of Multiple Intelligences: "The Stolen Painting" Game. In Proceedings of the International Conference on Games and Learning Alliance, Athens, Greece, 27-29 November 2019; Springer: Cham, Switzerland, 2019; pp. 490-500.

35. Anderson, E.F.; McLoughlin, L.; Liarokapis, F.; Peters, C.; Petridis, P.; De Freitas, S. Developing serious games for cultural heritage: A state-of-the-art review. Virtual Real. 2010, 14, 255-275. [CrossRef]

36. Mortara, M.; Catalano, C.E.; Bellotti, F.; Fiucci, G.; Houry-Panchetti, M.; Petridis, P. Learning cultural heritage by serious games. J. Cult. Herit. 2014, 15, 318-325. [CrossRef] 
37. Konstantakis, M.; Michalakis, K.; Aliprantis, J.; Kalatha, E.; Moraitou, E.; Caridakis, G. A methodology for optimised cultural user personas experience-CURE architecture. In Proceedings of the 32nd International BCS Human Computer Interaction Conference, Belfast, UK, 4-6 July 2018; pp. 1-8.

38. Streicher, A.; Smeddinck, J.D. Personalized and adaptive serious games. In Entertainment Computing and Serious Games; Springer: Cham, Switzerland, 2016; pp. 332-377.

39. Drosos, V.; Alexakos, C.; Alexandri, A.; Tsolis, D. Evaluating 3D Serious Games on Cultural Education. In Proceedings of the 2018 9th International Conference on Information, Intelligence, Systems and Applications (IISA), Zakynthos, Greece, 23-25 July 2018; IEEE: Piscataway, NJ, USA, 2018; pp. 1-5.

40. Galeazzi, F. Towards the definition of best 3D practices in archaeology: Assessing 3D documentation techniques for intra-site data recording. J. Cult. Herit. 2016, 17, 159-169. [CrossRef]

41. Pieraccini, M.; Guidi, G.; Atzeni, C. 3D digitizing of cultural heritage. J. Cult. Herit. 2001, 2, 63-70. [CrossRef]

42. Howe, J.; Robinson, M. The Rise of Crowdfunding. Revista Wired, 10 January 2008; p. 15.

43. Howe, J. The rise of crowdsourcing. Wired Mag. 2006, 14, 1-4.

44. Pandolfo, L.; Pulina, L.; Grosso, E. A user model ontology for adaptive systems in cultural tourism domain. In Applications of Intelligent Systems; IOS Press: Amsterdam, The Netherlands, 2018; pp. 212-219.

45. Rudan, E. The Development of Cultural Tourism in Small Historical Towns. In Faculty of Tourism and Hospitality Management in Opatija. Biennial International Congress. Tourism \& Hospitality Industry; University of Rijeka, Faculty of Tourism \& Hospitality Management: Rijeka, Croatia, 2010; p. 577.

46. Chen, G.; Huang, S. Understanding Chinese cultural tourists: Typology and profile. J. Travel Tour. Mark. 2018, 35, 162-177. [CrossRef]

47. Di Bitonto, P.; Laterza, M.; Rossano, V.; Roselli, T. A semantic approach implemented in a system recommending resources for cultural heritage tourism. J. e-Learn. Knowl. Soc. 2012, 8, 97-106.

48. Özel, Ç.H.; Kozak, N. Motive based segmentation of the cultural tourism market: A study of Turkish domestic tourists. J. Qual. Assur. Hosp. Tour. 2012, 13, 165-186. [CrossRef]

49. McKercher, B.; Ho, P. Cultural tourism and the enhancement of quality-of-life. In Handbook of Tourism and Quality-of-Life Research; Springer: Dordrecht, The Netherlands, 2012; pp. 341-357.

50. Vong, F. Application of cultural tourist typology in a gaming destination-Macao. Curr. Issues Tour. 2016, 19, 949-965. [CrossRef]

51. Nguyen, T.H.H.; Cheung, C. The classification of heritage tourists: A case of Hue city, Vietnam. J. Herit. Tour. 2014, 9, 35-50. [CrossRef]

52. Boulaalam, O.; Aghoutane, B.; El Ouadghiri, D.; Moumen, A.; Malinine, M.L.C. Design of a Tourism Recommendation System Based on User's Profile. In Proceedings of the International Conference on Advanced Intelligent Systems for Sustainable Development, Marrakech, Morocco, 8-11 July 2019; Springer: Cham, Switzerland, 2020; pp. 217-223.

53. Konstantakis, M.; Michalakis, K.; Aliprantis, J.; Kalatha, E.; Caridakis, G. Formalising and evaluating cultural user experience. In Proceedings of the 2017 12th International Workshop on Semantic and Social Media Adaptation and Personalization (SMAP), Bratislava, Slovakia, 9-10 July 2017; IEEE: Piscataway, NJ, USA, 2017; pp. 90-94.

54. Sin, A.K.; Zaman, H.B. Tangible interaction in learning astronomy through augmented reality book-based educational tool. In Visual Informatics: Bridging Research and Practice, Proceedings of the International Visual Informatics Conference, Kuala Lumpur, Malaysia, 11-13 November 2009; Springer: Berlin/Heidelberg, Germany, 2009; pp. 302-313.

55. Hta, A.C.Z.; Lee, Y. Interactive spatial augmented reality book on cultural heritage of Myanmar. J. Inf. Commun. Converg. Eng. 2020, 18, 69-74.

56. Desierto, A.J.R.; Reciña, A.S.A.; Arroyo, J.C.T.; Delima, A.J.P. GoonAR: A bilingual children storybook through augmented reality technology using unity with Vuforia framework. Int. J. Adv. Trends Comput. Sci. Eng. 2020, 9. [CrossRef]

57. Huang, Y.; Rodriguez Echavarria, K.; Julier, S. Engaging audiences with Cultural Heritage through Augmented Reality (AR) Enhanced Pop-Up Books. In Eurographics Workshop on Graphics and Cultural Heritage; The Eurographics Association: Geneve, Switzerland, 2020.

58. Belloli, S.; Porro, S.; Virk, V.S.; Etzi, R.; Gallace, A.; Bordegoni, M.; Carulli, M. The Kandinsky experience: A multisensory augmented reality application for cultural heritage. Comput.-Aided Des. Appl. 2020, 18, 799-814. [CrossRef]

59. Román-Graván, P.; Ballesteros-Regaña, C.; Hervás-Gómez, C. Perceptions of future primary school teachers on the use of augmented reality in educational contexts. In Interactive Experiences with Augmented Reality in Classrooms; Editorial Octaedro: Barcelona, Spain, 2016; pp. 101-119, ISBN 978-84-9921-867-0. 